\title{
PERANCANGAN SISTEM SMARTCARD SEBAGAI PENGAMAN PINTU MENGGUNAKAN RFID BERBASIS ARDUINO
}

\author{
Ferry Sudarto ${ }^{1}$ \\ Gustasari $^{2}$ \\ Arwan $^{3}$ \\ Dosen Jurusan Sistem Komputer STMIK Raharja ${ }^{1}$, Alumni STMIK Raharja Jurusan Sistem Komputer ${ }^{2}$, \\ Alumni STMIK Raharja Jurusan Sistem Komputer ${ }^{3}$ \\ Email:ferry.sudarto@raharja.info,gustasari@raharja.info,arwan@raharja.info
}

Diterima: 6 Juni 2017/ Disetujui : 13 Juni 2017

\begin{abstract}
Along with the development of science and technology so rapidly trigger the emergence of new technologies, one of which is RFID. RFID (Radio Frequency Identification) is a process of identifying the object or objects using radio transmission frequency. RFID is a new technology, and will continue to evolve in line with advances in integrated circuit technology, it can be ascertained that the RFID tag can be applied in various fields. RFID systems offer increased efficiency in controlling inventory control in the identification of objects. RFID can be used to store and receive data remotely using a device that RFID TAG (transponder). Many applications can utilize RFID systems, for example for indoor security systems, highways, libraries, class attendance, even as the identity of the student / students. Therefore, in this researchRaharja College presenting a Smartcard System Design using RFID as a device interface and ARDUINO UNO as a controller to be used as a door security system. With the presence of this system is expected to be a useful new innovation in Raharja College and can improve the shortcomings of existing systems and can provide maximum service to the whole personal raharja.
\end{abstract}

Keywords: RFID, TAG, ARDUINO UNO, Smartcard.

\begin{abstract}
ABSTRAK
Seiring dengan perkembangan ilmu pengetahuan dan teknologi yang begitu pesat memicu munculnya berbagai teknologi baru yang salah satunya adalah RFID. RFID ( Radio Frequency Identification) adalah suatu proses identifikasi benda atau objek dengan menggunakan frekuensi transmisi radio. RFID merupakan suatu teknologi baru, dan akan terus berkembang seiring dengan kemajuan teknologi rangkaian terintegrasi, maka dapat dipastikan bahwa tag RFID dapat diaplikasikan dalam berbagai bidang. Sistem-sistem RFID menawarkan peningkatan efisien dalam pengendalian inventory control dalam indentifikasi benda. RFID bisa digunakan untuk menyimpan dan menerima data secara jarak jauh dengan menggunakan suatu piranti yaitu RFID TAG (transponder). Banyak aplikasi yang dapat memanfaatkan sistem RFID, misalnya untuk sistem keamanan ruangan, jalan tol, perpustakaan, absensi kelas, bahkan sebagai identitas mahasiswi/mahasiswa. Oleh karena itu pada penelitian ini Perguruan Tinggi Raharja menghadirkan sebuah Perancangan Sistem Smartcard dengan menggunakan RFID sebagai device interface dan ARDUINO UNO sebagai pengontrolnya untuk dijadikan sebagai sistem pengamanan pintu.Dengan hadirnya sistem ini diharapkan dapat menjadi sebuah inovasi baru yang berguna pada Perguruan Tinggi Raharja dan dapat memperbaiki kekurangan sistem yang sudah ada serta dapat memberikan pelayanan yang maksimal kepada seluruh pribadi raharja.
\end{abstract}

Kata Kunci: RFID, TAG, ARDUINO UNO, Smartcard. 


\section{PENDAHULUAN}

Seiring dengan perkembangan ilmu pengetahuan dan teknologi yang begitu pesat memicu munculnya berbagai teknologi baru yang salah satunya adalah RFID. RFID ( Radio Frequency Identification) adalah suatu proses identifikasi benda atau objek dengan menggunakan frekuensi transmisi radio. RFID merupakan suatu teknologi baru, dan akan terus berkembang seiring dengan kemajuan teknologi rangkaian terintegrasi, maka dapat dipastikan bahwa tag RFID dapat diaplikasikan dalam berbagai bidang. Diantaranya dalam hal identifikasi yang bergerak di bidang logistik, pergudangan, manufaktur, pelayanan keamanan,dll. RFID sendiri merupakan pengembangan dari sistem identifikasi sebelumnya, yaitu barcode. Perbedaan yang mendasar antara RFID dan barcode terletak pada cara scanning. Untuk barcode biasanya scanning dilakukan secara langsung dan posisi antara tag dengan reader harus benar, jika tidak maka tag tersebut tidak dapat terbaca oleh reader. Berbeda dengan RFID yang hanya mendekatkan tag ke reader, maka tag tersebut dapat teridentifikasi.

Banyak aplikasi yang dapat memanfaatkan sistem RFID, misalnya untuk sistem keamanan ruangan, jalan tol, perpustakaan, absensi kelas, bahkan sebagai identitas mahasiswi/mahasiswa. Sistem RFID terdiri dari 3 (tiga) komponen utama, yaitu tag atau transponder, reader, dan database. Tag RFID berfungsi sebagai alat pelabelan suatu objek yang di dalamnya terdapat sebuah data objek tersebut. Reader berfungsi sebagai alat yang digunakan untuk scanning atau pembaca informasi yang ada pada tag RFID. Sedangkan database berfungsi sebagai alat penyimpanan informasi objek yang dimiliki oleh tag RFID.

Penggunaan RFID semakin meluas khusunya di Indonesia, yang membuat para ahli berlomba - lomba untuk mengembangkannya.Perguruan Tinggi Raharja merupakan salah satu institusi pendidikan yang bergerak di bidang teknologi informasi.Untuk itu, Perguruan Tinggi Raharja terus menerus melakukan peningkatan dan pengembangan, baik berupa sistem pembelajaran kampus maupun sistem pelayanan yang ditetapkan di Perguruan Tinggi Raharja.

Sebagai bentuk pelayanan yang maksimal kepada seluruh pribadi raharja, Perguruan Tinggi Raharja menghadirkan sebuah Perancangan Sistem Smartcard sebagai pengaman pintu menggunakan RFIDberbasis Arduino.Dengan hadirnya sistem ini diharapkan dapat menjadi sebuah inovasi baru yang berguna pada Perguruan Tinggi Raharja dan dapat memperbaiki kekurangan sistem yang sudah ada.

\section{PERMASALAHAN}

Sebuah system pengaman digunakan sekarang ini adalah sebuah sistem pengamanan yang masih konvensional dengan menggunaan kunci dan gembok, dan dirasakan sistem pengamanan ini kurang efektif dalam mengamankan ruangan dibuktian dengan banyak ruangan-ruangan yang menyimpan barang-barang berharga mudah dibobol oleh para penjahat. Belum lagi dengan berkembangnya ilmu pengetahuan dan teknologi yang begitu pesat haruslah sebuah instansi pendidikan khususnya Perguruan Tinggi Raharja sebagai instansi atau Perguruan Tinggi yang bergerak dalam bidang Teknologi dan Informasi haruslah berkembang dengan menciptakan inovasiinovasi baru dalam bidang IT, agar tidak tertinggal oleh instansi-instansi lain yang bergerak dalam bidang yang sama.

Belakangan ini sudah tercipta beberapa sistem-sistem pengamanan ruangan yang berbasis Teknologi Informasi, diantaranya seperti sistem pengamanan ruangan berbasis kartu (swipe card), sistem pengamanan ruangan berbasis sidik jari, sistem pengamanan ruangan berbasis suara, dan sistem pengamanan ruangan berbasis biometric lainya. Namun untuk sistem pengamanan berbasis kartu sudah jarang sekali digunakan karena sistem pengamanan ini dirasakan sudah kurang efisien dan tertinggal dengan sistem pengamananruangan berbasis biometric lainnya dikarenakan sistem kartu ini biasanya hanya menggunakan pita magnetic, seperti sistem berbasis swipe card.Sedangkan untuk sistem pengamanan ruangan berbasis kartu dengan radio frekuensi seperti RFID jarang sekali digunakan karena sistem ini belum lama dikembangkan. 


\section{METODE PENELITIAN}

\section{Metode Pengumpulan Data}

\section{Pengamatan (Observation)}

Merupakan metode pengumpulan data melalui pengamatan langsung atau peninjauan secara cermat dan langsung di lapangan atau lokasi penelitian. Penelitian ini dilakukan pada Perguruan Tinggi Raharja yang menjadi lokasi penelitian guna memperoleh data dan keterangan yang berhubungan dengan jenis penelitian.

\section{Wawancara}

Merupakan metode pengumpulan data dengan jalan tanya jawab sepihak yang dilakukan secara sistematis dan berlandaskan kepada tujuan penelitian ( Lerbin, 1992 dalam Hadi, 2007 ). Pada metode ini penulis melakukan proses tanya jawab kepada beberapa narasumber pada objek penelitian yaitu proses tanya jawab yang dilakukan secara langsung kepada pembimbing.

\section{Studi Pustaka}

Studi Pustaka adalah segala upaya yang dilakukan oleh peneliti untuk memperoleh dan menghimpun segala informasi tertulis yang relevan dengan masalah yang diteliti. Informasi ini diperoleh dari buku-buku, laporan penelitian, tesis atau disertasi, peraturan-peraturan, ketetapanketetapan dan sumber- sumber lain.Pada metode ini penulis akan mendapatkan informasi dengan mempelajari buku-bukudan literature yang ada. Pada metode ini penulis akan mendapatkan informasi dengan memepelajari buku- buku dan literatur yang ada seperti CCIT Journal Perguruan Tinggi Raharja.

\section{Metode Analisa}

Analisis data merupakan salah satu langkah penting dalam rangka memperoleh temuan-temuan hasil penelitian. Hal ini disebabkan, data akan menuntun kita ke arah temuan ilmiah, bila dianalisis dengan teknik- teknik yang tepat. Analisis sistem dilakukan menggunakan Metode Analisa SWOT, yaitu Kekuatan (Strengths), Kelemahan (Weakness), Kesempatan (Oppurtunities), dan yang menjadi Ancaman (Threats). Analisa SWOT dapat diterapkan dengan cara menganalisis dan memilah berbagai hal yang mempengaruhi keempat faktornya, kemudian menerapkannya dalam gambar matrik SWOT dengan menggunakan pendekatan pemecahan masalah menggunakan konsep Service Marketing Mix (Bauran Pemasaran Jasa) 7P-Product, Price, Promotion,Place, People, Process, dan Physical Evidence.

\section{Metode Perancangan}

Dalam melakukan perancangan penulis menggunakan metode Flow Chart dan Mind Mapping dengan Menjabarkan setiap tahapan kerja dari sistem yang akan dibuat.

\section{LITERATURE REVIEW}

Banyak penelitian yang sebelumnya dilakukan mengenai Perancangan Sistem Pengamanan Ruangan menggunakan RFID. Dalam upaya mengembangkan dan menyempurnakan penelitian ini dibutuhkan study pustaka (literature review) sebagai salah satu dari penerapan metode penelitian yang akan dilakukan. Beberapa Penelitian yang ada diantaranya yaitu :

1. Penelitian ini dilakukan oleh Muharrir Riza ${ }^{[1]}$, pada tahun 2014 dari Universitas Ubudiyah, Indonesia yang berjudul "PERANCANGAN KEAMANAN PINTU OTOMATIS BERBASIS RFID (RADIO FREKUENSI IDENTIFICA TION)" . Penelitian ini membahas tentang cara menggabungkan penguncian pintu manual dengan sistem RFID. Membuat sistem pembacaan data RFID terhadap kartu tag RFID dengan menggunakan modul ID-12 dan membuatsistem yang dapat memverikasi nomor identitas user pada kartu RFID menggunakan mikrokontroler 
ARDUINO.

2. Penelitian ini dilakukan oleh Darmawan Denny Diredja, Ramdhani, M. dan Ary M Murti ${ }^{[2]}$ dari Fakultas Elektro dan Komunikasi - Institut Teknologi Telkom, pada tahun 2010 yang berjudul "PERANCANGAN SISTEM PENGAMAN PINTU MENGGUNAKAN RFID TAG CARD DAN PIN BERBASIS MIKROKONTROLER AVR ATMEGA 8535". Penelitian ini membahas tentang Perancangan sistem pengaman yang menggunakan kunci elektronik wireless RFID Tag Card. RFID adalah salah satu produk dari pengembangan teknologi nirkabel yang saat ini terus diaplikasikan dalam kehidupan sehari-hari.Inti dari teknologi ini adalah RFID Tag Card yang mampu memancarkan data yang hanya dapat diterima oleh RFID Reader.Untuk memberikan pengamanan berlapis maka digunakan pula password dalam pengaksesan pintu.

3. Penelitian ini dilakukan oleh Damas Cahyo Saputro, Yuniarto,ST. MT. [3], Universitas Diponegoro Semarang, pada tahun 2012 yang berjudul "APLIKASI RADIO FREQUENCY IDENTIFICATION DAN INFRARED SEBAGAI PENGAMAN PINTU KELUAR MASUK BERBASIS MIKROKONTROLER AVR ATMEGA 16 PADA MINIATUR KOMPLEKS PERUMAHAN MODERN". Penelitian ini membahas tentang sistem keamanan komplek perumahan modern menggunakan palang pintu keluar masuk kompleks perumahan modern.Dengan perkembangan teknologi, sistem tersebut dapat diatur secara otomatis oleh mikrokontroller A VR Atmega 16 dengan Radio Frequency Identification (RFID) dan Infra Red (IR).

4. Penelitian ini dilakukan oleh Abri Putra, Johannes Sipahutar, Setiawardhana, dan Dwi Kurnia Basuki ${ }^{[4]}$, dari Politeknik Elektronika Negeri Surabaya - Institut Teknologi Sepuluh Nopember (ITS) Surabaya, pada tahun 2011 yang berjudul "SISTEM IDENTIFIKASI SMARTCARD-RFID DAN PENGENALAN TANDA TANGAN MENGGUNAKAN METODE BACKPROPAGATION DENGAN KOHONEN SEBAGAI PEMBANDING ". Penelitian ini membahas tentang rancangan sebuah sistem pengaman pintu dengan sistem keamanan elektrik berbasis smartcard dan identifikasi pola tanda tangan dengan metode jaringan saraf tiruan.

5. Penelitian ini dilakukan oleh Johan Wijaya Kusuma dan Sigit Nugoho ${ }^{[5]}$ dari AMIK GI MDP , pada tahun 2012 yang berjudul "PENGAMAN RUMAH MENGGUNAKAN KUNCI ELEKTRONIK BERBASIS RFID". Penelitian ini membahas tentang uji coba untuk diaplikasikan diberbagai peralatan yang masih menggunakan kunci mekanik biasasebagai pembukanya.

6. Penelitian ini dilakukan oleh Claudia Nasution, Dewi Puji Rahayu Tampubolon, dan Jenetha Friscilia Simangunsong ${ }^{[6]}$ dari Politeknik Negeri Medan, pada tahun 2014 yang berjudul "PERANCANGAN DAN PEMBUATAN SIMULASI SISTEM KEAMANAN PINTU DENGAN SISTEM CALLING SELULER MENGGUNAKAN RFID (RADIO FREQUENCY IDENTIFICATION) DAN PASSWORD BERBASIS MIKROKONTROLER ATMEGA16". Penelitian ini membahas tentang sistem keamanan yang dilengkapi dengan sistem pasword dan menggunakan RFID.

7. Penelitian ini dilakukan oleh Didik Suyoko ${ }^{[7]}$, dari Universitas Negeri Y ogyakarta, pada tahun 2012 yang berjudul "ALA T PENGAMAN PINTU RUMAH MENGGUNAKAN RFID(RADIO FREQUENCY IDENTIFICATION) 125 KHZ BERBASIS MIKROKONTROLER ATMEGA328". Penelitian ini membahas tentang pengaman pintu menggunakan RFID.

8. Penelitian ini dilakukan oleh Anggun Rahmadani Prativi dan Rafika Napitupulu ${ }^{[8]}$ Politeknik Negeri Medan, pada tahun 2013 yang berjudul "RANCANG BANGUN SISTEM KEAMANAN PINTU DENGAN MENGGUNAKAN RFID BERBASIS MIKROKONTROLER AT89S52". Penelitian ini membahas tentang cara membangun sistem keamanan pintu menggunakan RFID dan suatu sistem keamanan pintu menggunakan password sebagai kunci digitalnya.

9. Penelitian ini dilakukan oleh Rimhot OmriI Tua Situmeang ${ }^{[9]}$ dari Universitas Sumatera Utara, pada tahun 2011 yang berjudul "PERANCANGAN SISTEM KEAMANAN PINTU MENGGUNAKAN RFID BERBASIS MIKROKONTROLERA TMEGA8535". Penelitian ini membahas tentang "Perancangan Sistem Keamanan Pintu Menggunakan RFID Berbasis 
Mikrokontroler ATMEGA 8535". Aplikasi radio Frequency Identification ( RFID ) adalah salah satu aplikasi RFID yang dikembangkan disini adalah sebagai kunci pintu otomatis.

10. 10. Penelitian ini dilakukan oleh Nurul Komaeni ${ }^{[10]}$ dari Perguruan Tinggi Raharja, Tangerang, pada tahun 2015 yang berjudul "ANALISA PERPUSTAKAAN MENGGUNAKAN ACR 122U BERBASIS RFID PADA PERGURUAN TINGGI RAHARJA". Penelitian ini membahas tentang proses peminjaman buku pada perpustakaan dengan menggunakan RFID. Maka diperlukan proses yang cepat dan efisien agar dapat menyelesaikan masalah yang terjadi diatas. Saat ini proses peminjaman dan pemindahan data masih semi-komputer.

Dari kesepuluhliterature review yang ada, telah banyak penelitian mengenai Sistem Pengamanan Ruangan menggunakan RFID. Namun dapat disimpulkan pula bahwa masih jarangnya peneliti yang secara khusus merancang sistem pengamanan ruangan RFID yang berbasis pada Arduino.Dimana Arduino itu sendiri merupakan sebuah modul device kontrol yang sudah terdapat mikrokontroller di dalamnya.

\section{PEMBAHASAN}

\section{Analisa Sistem Yang Berjalan}

Untuk menganalisa sistem yang sedang berjalan saat ini, maka penelitian ini menggunakan program Flowchartdan Aplikasi SimpleMind dalam bentuk Mind Map untuk menggambarkan prosedur dan proses yang berjalan saat ini.

\section{Analisa Sistem Yang Berjalan Pada Flowchart}

Pada tahap pembuatan sebuah kontrol diperlukan sebuah gambar yang nantinya akan menjelaskan suatu alur atau langkah-langkah dari sebuah kerja sistem yang dibuat, sehingga dapat memberikan penjelasan dalam bentuk gambar. Penjelasan yang berupa gambar proses kerja sebuah sistem yang merupakan gambar dari sistem yang dibuat. Tujuan dari pembuatan flowchartadalah untuk mempermudah pembaca dan pembuat sistem itu sendiri untuk memahami langkah-langkah serta cara kerja sebuah sistem yang dibuat. Dari penelitian yang dilakukan menghasilkan flowchart, seperti gambar 1 dibawah ini : 


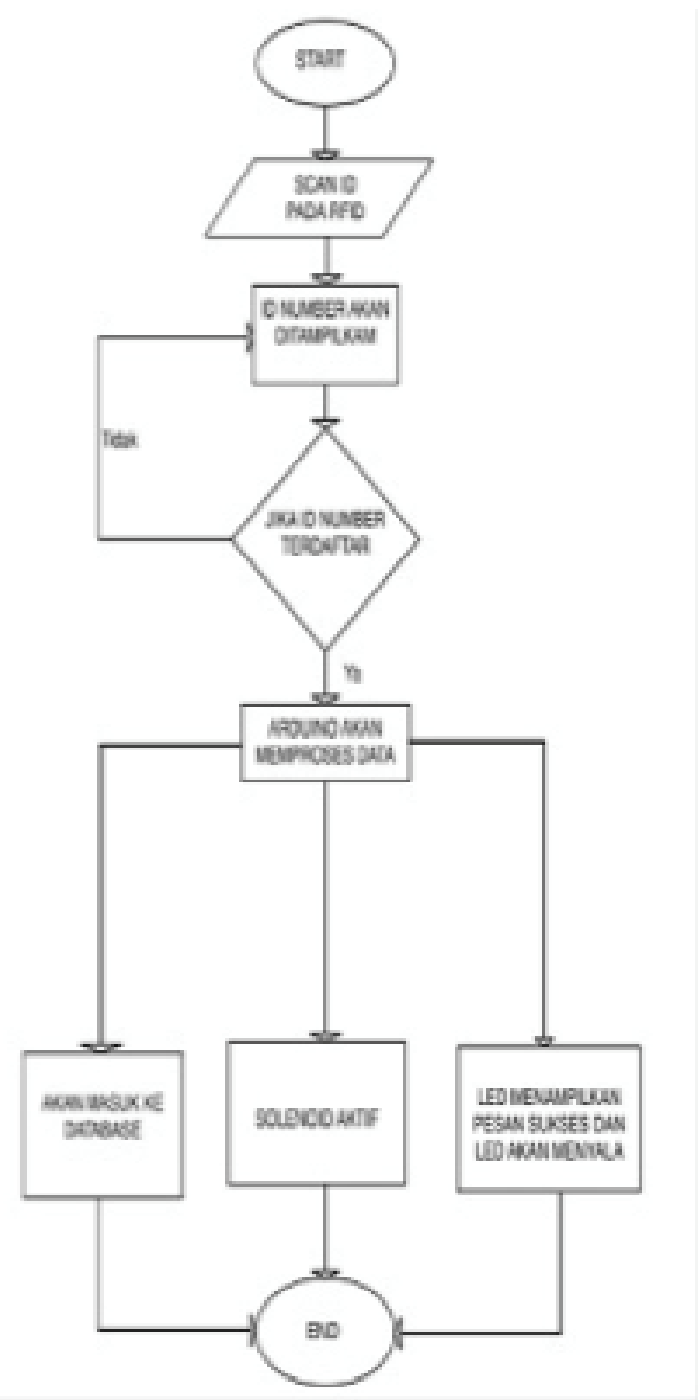

Gambar 1. Flowchart sistem SmartCard

Terlihat dari Gambar 1 menjelaskan bahwa ketika melakukan scan rfid maka id number akan tampil, dan jika benar atau id number terdaftar maka arduino akan memproses data,tetapi jika terjadi kesalahan atau id number belum terdaftar maka proses data akan kembali di posisi sebelumnya. Data yang benar nantinya akan tersimpan kedalam database lalu terdapat indicator melalui led yang menyala serta menampilkan pesan sukses, lalu solenoid akan mendapat peintah untuk membuka pintu. Berikut ini perancangan system smartcardmelaluimindmapping, seperti gambar 2 dibawah ini: 


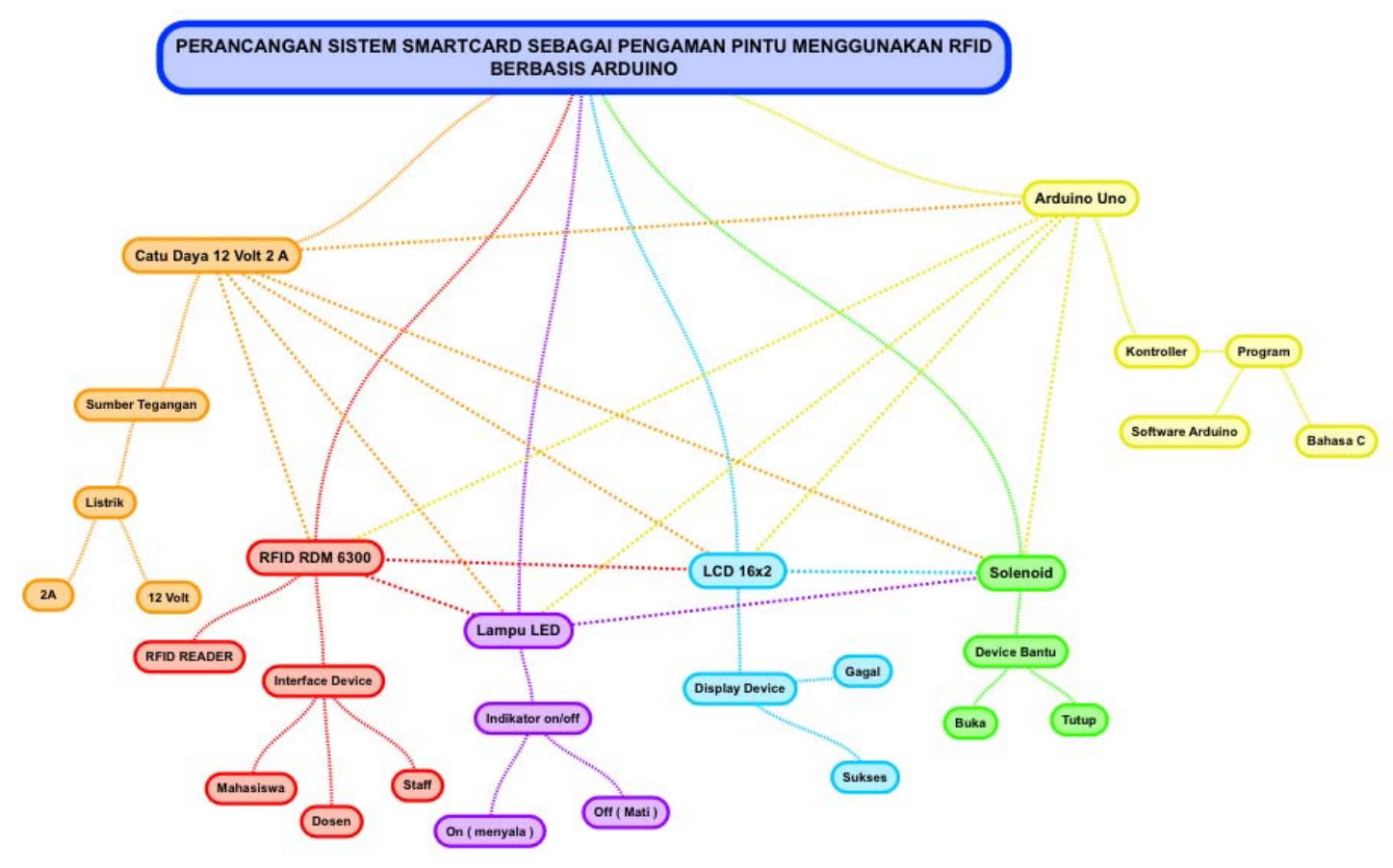

Gambar 2. Mind Mapping System SmartCard

\section{Perancangan Perangkat Keras}

Dalam perancangan perangkat keras ini dibutuhkan beberapa komponen elektronika device penunjang agar sistem dapat berjalan dengan baik sesuai dengan fungsinya. Dalam perancangan perangkat keras ini, alat dan bahan yang dibutuhkan adalah :

a. Alat-alat yang digunakan

1. Personal Computer (PC)

2. Software Arduino

3. Solder

4. timah

5. Penyedot timah

6. Arduino Uno sebagai boot loader untuk upload program

b. Bahan-bahan yang digunakan

1. Arduino Uno

2. Rfid rdm6300

3. Keypad 16x2 display

4. Solenoid

5.Buzzer

6.Heatshink (alumunium pendingin).

7.Lampu led Biru

8.Resistor $10 \mathrm{kohm}, 330 \mathrm{ohm}$.

9.Kapasitor keramik 22 pf. Kapasitor Elco $2200 \mathrm{microFarad} / 35 \mathrm{volt}, 100 \mathrm{microFarad} / 16 \mathrm{volt}$

10.KapasitorElco $2200 \mathrm{microFarad} / 35 \mathrm{volt}, 100 \mathrm{microFarad} / 16$ volt

11.Kabel Jumper.

Agar mempermudah penulis dalam menjelaskan perancangan perangkat keras, maka di gambarkan alur dan cara kerja perangkat keras pada rangkaian diagram blok pada gambar 3 di bawah ini: 


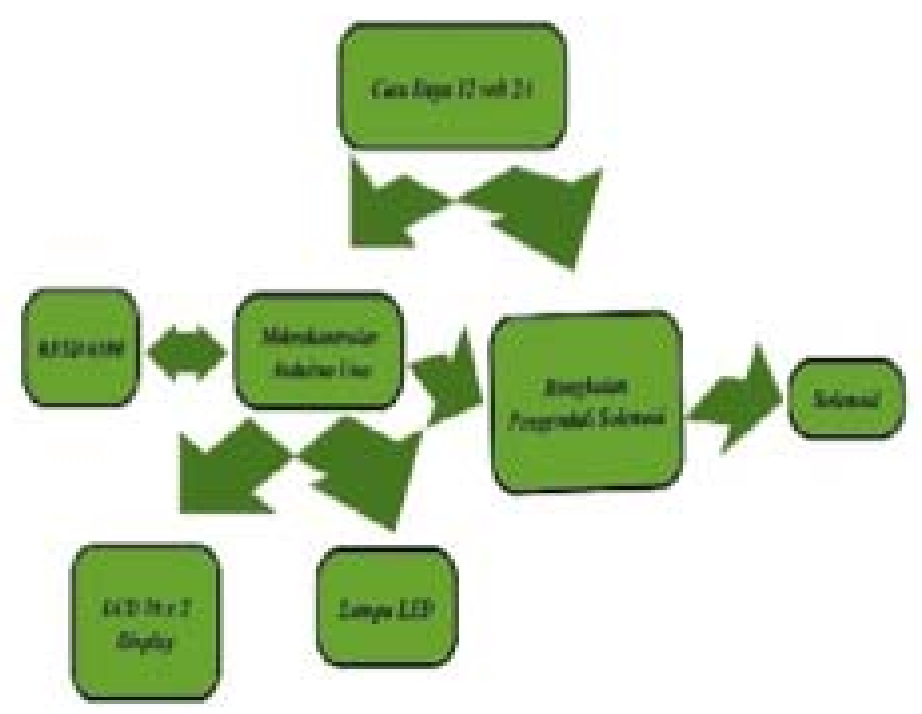

Gambar 3. Diagram Blok Rangkaian

Pada Gambar 3 merupakan alur dari diagram blok, dimana terdapat konfigurasi seluruh rangkaian yang digunakan. Prinsip dari kerja sistem yang di rancang adalah Card RFID menjadi media untuk memberikan inputan pada Arduino Uno, ketika Arduino Uno menerima inputan dari Card RFID maka inputan tersebut akan menjadi perintah untuk Solenoid agar bisa berfungsi atau tidak berfungsi. Dan ketika Arduino Uno menerima inputan dari Card RFID, maka inputan tersebut akan menjadi perintah baik itu untuk Solenoid, tergantung Card RFID mana yang di dekatkan atau di tempelkan pada RFID Reader.

\section{Konsep Dasar RFID RDM 6300}

RFID RDM 6300 adalah modul reader rfid yang berfungsi sebagai pembaca RFID. RFID RDM6300 adalah pengganti dari reader RDM 630 yang barangnya sudah tidak diproduksi lagi alias discontinued Update version terbaru adalah reader RFID RDM 6300 yang memiliki sensifitas jarak yang lebih jauh dan stabil. Tapi pin out dari kedua RFID ini sama persis. Berikut ini tampilan RFID RDM 6300, seperti gambar 4 dibawah ini :

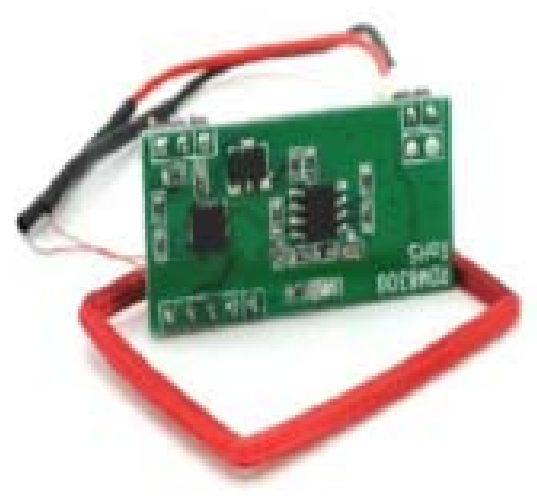

Gambar 4.RFID RDM 6300

\section{Konsep Dasar Arduino Uno}

Arduino Uno sebenarnya adalah salah satu kit mikrokontroler yang berbasis pada Atmega328.Modul ini sudah dilengkapi dengan berbagai hal yang dibutuhkan untuk mendukung mikrokontroler untuk bekerja, tinggal colokkan ke power suplyatau sambungkan melalui kabel USB 
ke PCmu Arduino Uno ini sudah siap sedia. Arduino Uno ini memilki 14 pin digital input/output, 6 analog input, sebuah resonator keramik $16 \mathrm{MHz}$, koneksi USB, colokan power input, ICSP header, dansebuah tombol reset. Berikut ini tampilan arduino uno, seperti gambar 5 dibawah ini :

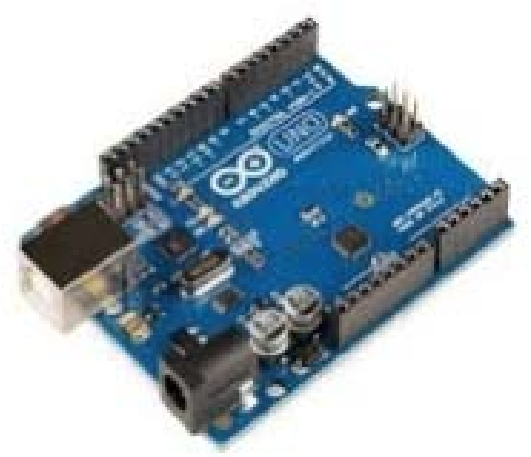

Gambar 5. Arduino UNO

\section{Konsep Dasar LCD 16x2}

LCD Karakter adalah LCD yang tampilannya terbatas pada tampilan karakter, khususnya karakter ASCII (seperti karakter-karakter yang tercetak pada keyboard komputer). Sedangkan LCD Graphics = LCD Grafik, adalah LCD yang tampilannya tidak terbatas, bahkan dapat menampilkan foto. LCD Grafik inilah yang terus berkembang seperti layar LCD yang biasa dilihat di notebook / laptop. Dalam pembahasan kali ini akan dikonsentrasikan pada LCD Karakter. Berikut ini tampilan LCD 16x2 dan banyaknya karakter yang dapat ditampilkan, seperti gambar 6, dan gambar 7 dibawah ini :

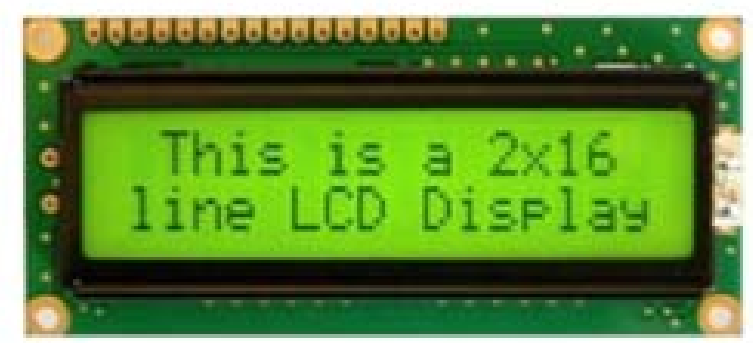

Gambar 6. LCD 16x2

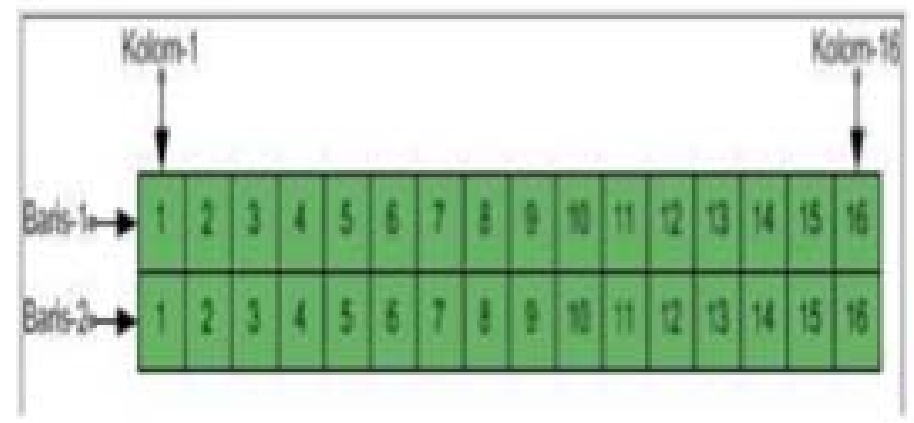

Gambar 7. Banyaknya karakter yang dapat ditampilkan

Untuk dapat mengendalikan LCD karakter dengan baik, tentu perlu koneksi yang benar. Dan koneksi yang benar dapat diwujudkan dengan cara mengetahui pin-pin antarmuka yang dimiliki oleh LCD karakter tersebut. LCD karakter yang beredar di pasaran memiliki 16 pin antarmuka, seperti gambar 8 dibawah ini: 


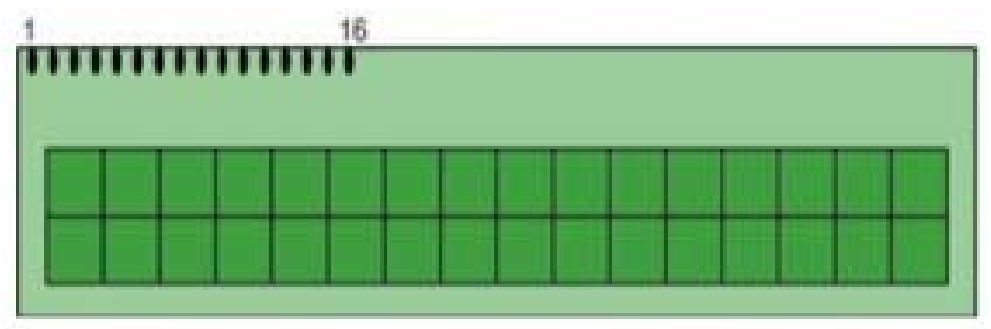

Gambar 8. Banyaknya pin yang digunakan

Keterangan :

4. $\mathrm{VCC}=$ GND.

5. $\quad \mathrm{VDD}=$ positif $5 \mathrm{~V}$.

6. V o : tegangan untuk mengatur kontras dari tampilan karakter.

7. RS.

8. $\mathrm{R} / \mathrm{W}$.

9. $\mathrm{E}=$ pin4(RS)-pin6(E) digunakan untuk aktivasi LCD

10. DB0.

11. h.DB1.

12. DB2.

13. DB3.

14. DB4.

15. DB5.

16. DB6.

17. Anoda LED backlight LCD.

18. Katoda LED backlight LCD.

19. DB7.

\section{Konsep Dasar Solenoid}

Solenoid adalah salah satu jenis kumparan terbuat dari kabel panjang yang dililitkan secara rapat dan dapat diasumsikan bahwa panjangnya jauh lebih besar daripada diameternya. Dalam kasus solenoid ideal, panjang kumparan adalah tak hingga dan dibangun dengan kabel yang saling berhimpit dalam lilitannya, dan medan magnet di dalamnya adalah seragam dan paralel terhadap sumbu solenoid. Berikut ini tampilan solenoid, seperti gambar 9 dibawah ini :

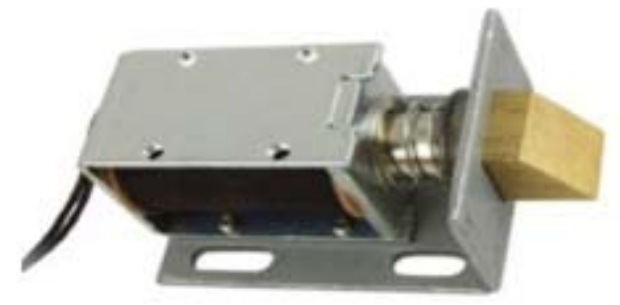

\section{Gambar 9. Solenoid}

\section{Perancangan Perangkat Lunak}

Perancangan perangkat lunak adalah melakukan penulisan listing program ke dalam software Arduino 1.0 dengan menggunakan bahasa $\mathrm{C}$, dimana perintah-perintah program tersebut akan di eksekusi oleh hardware atau sistem yang dibuat.

\section{Konsep Dasar Bahasa C}

Bahasa $\mathrm{C}$ adalah salah satu dari banyak bahasa pemrograman desktop yang cukup populer dan mempunyai cukup banyak keunggulan. Ada banyak aplikasi-aplikasi yang dirancang dalam bahasa $\mathrm{C}$, atau mungkin paling tidak struktur utama programnya ditulis dalam bahasa $\mathrm{C}$. Bahasa $\mathrm{C}$ 
adalah sebuah bahasa dasar tingkat menengah yang sifatnya kompleks dan membangun logika atau algoritma. Kenapa dikatakan tingkat menengah karena $\mathrm{C}$ bisa masuk ke tingkat Tinggi maupun rendah.Software Development Kit untuk Windows juga dirancang / tulis dalam bahasa C. Bahasa C berifat portable, yaitu dengan sedikit atau tanpa perubahan, suatu program yangdirancang / tulis dengan bahasa $\mathrm{C}$ dapat dijalankan pada komputer lain.

\section{Strategi Proyek}

Dalam pemecahan masalah diatas, maka diperoleh beberapa strategi dalam tahap pengembangan sistem RFID pada Perguruan Tinggi. Strategi ini dimanfaatkan sebagai tolak ukur kebutuhan sistem yang akan diusulkan. Berikut tabel strategi pengembangan sistem $R F I D$, seperti gambar 10 dibawah ini :

\begin{tabular}{|c|c|}
\hline \multicolumn{2}{|r|}{ Sintre IXIil } \\
\hline Stropi $y n$ & Pabein alt lapeven \\
\hline 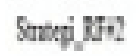 & Yonipgt thidid ced \\
\hline Sextiplys & 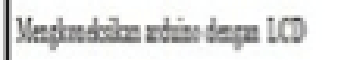 \\
\hline Strati.kFH & 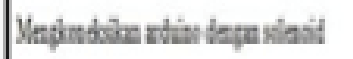 \\
\hline Strutioges & 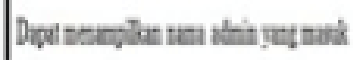 \\
\hline Saxtiplys & Yalatatedait \\
\hline 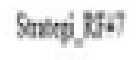 & 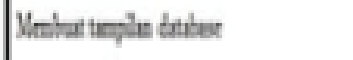 \\
\hline Saxpiphas & 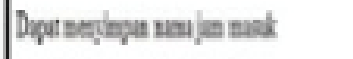 \\
\hline saretijev & 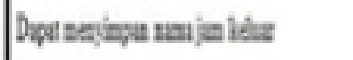 \\
\hline Sutegi RE:10 & Yespocis ix hespes \\
\hline
\end{tabular}

Gambar 10. Strategi RFID

\section{UJI COBA DAN IMPLEMENTASI}

\section{Penulisan Listing Program Bahasa C}

Pada perancangan perangkat lunak mengumpulkan program arduino 1.0 digunakan untuk menuliskan listing program dan menyimpannya dengan file yang berektensi.Pde dan bootlloader Arduino 1.0 sebagai media yang digunakan mengupload program ke dalam Arduino Uno, sehingga Arduino Uno dapat bekerja sesuai dengan yang diperhatikan.

Adapun langkah-langkah untuk memulai menjalankan software Arduino 1.0 dapat dilihat seperti pada gambar 11 sebagai berikut : 


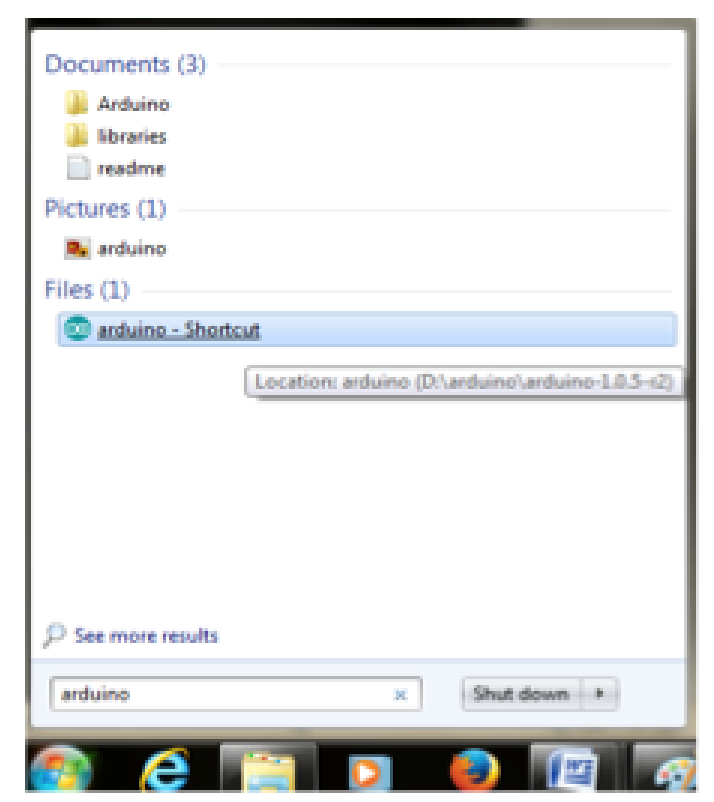

Gambar 11. Membuka Program Arduino 1.0

Setelah langkah pada gambar di atas dilakukan, agar sistem dapat bekerja sesuai dengan yang dinginkan, selanjutnya lakukan penulisan listing program secara keseluruhan.

Setelah listing program ditulis semua, langkah selanjutnya adalah proses kompilasi untuk mengecek apakah listing program yang ditulis terjadi kesalahan atau tidak, proses kompilasi dapat dilihat pada gambar 12 dibawah ini :

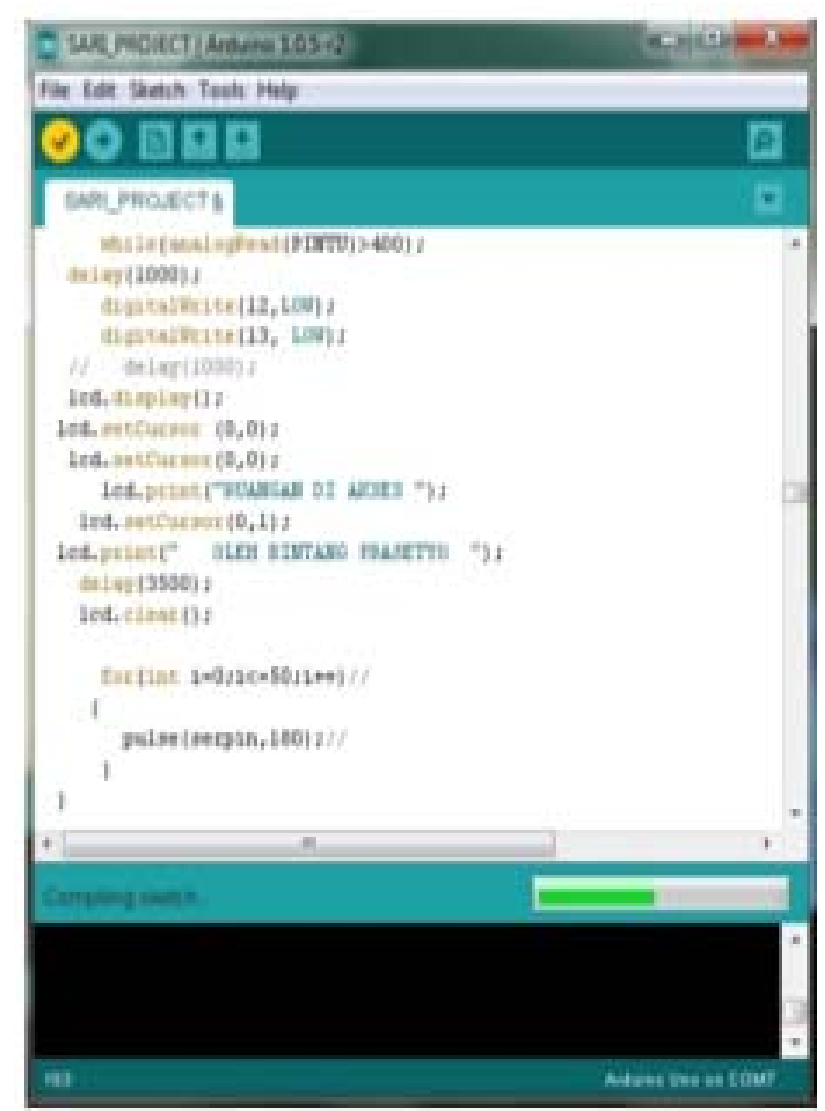

Gambar 12. Proses Compile Program

Pada gambar 13 dibawah ini menunjukan hasil dari kompilasi listing program dan hasil dari 
proses kompilasi tersebut tidak terjadi error, artinya proses penulisan listing program sudah benar, hasil dari kompilasi inilah yang akan ditanamkan ke dalam sistem Arduino Uno.

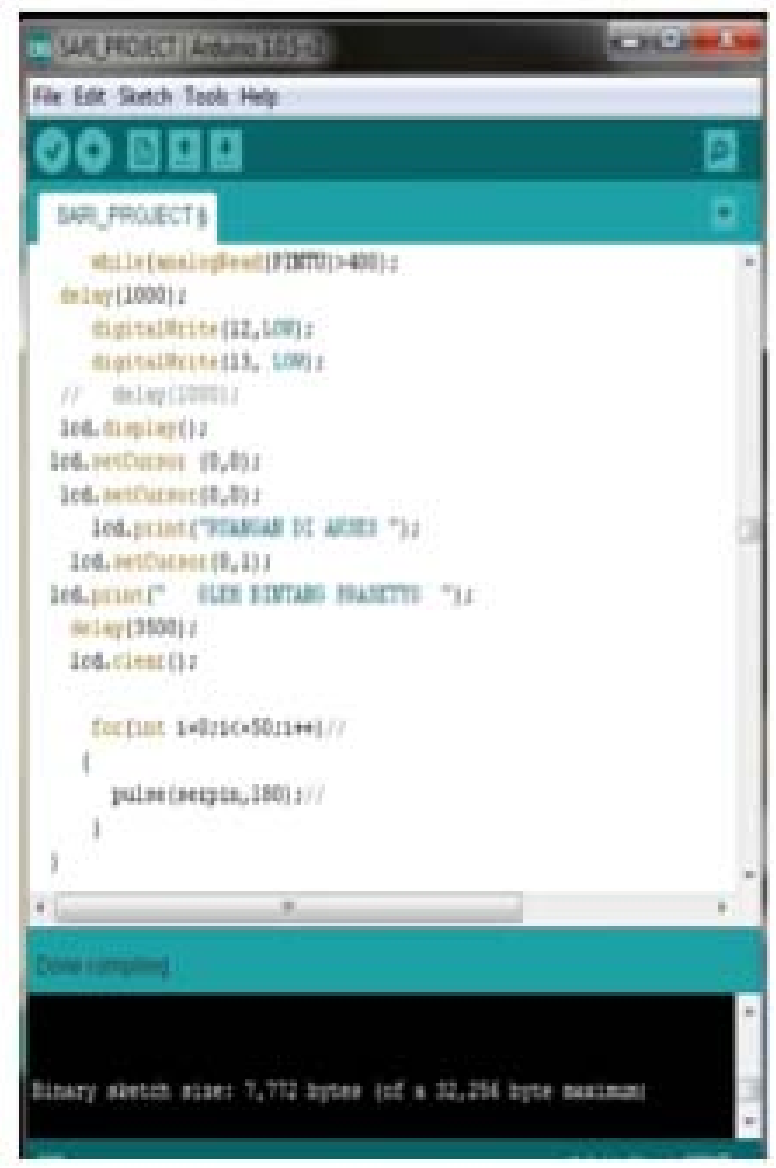

Gambar 13. Proses Compile Program

Pada saat mengupload listing program secara otomatis akan menampilkan pesan bahwa proses upload program tidak terjadi error atau sukses. Proses upload listing program yang tidak terjadi error dapat dilihat pada gambar 14 sebagai berikut: 


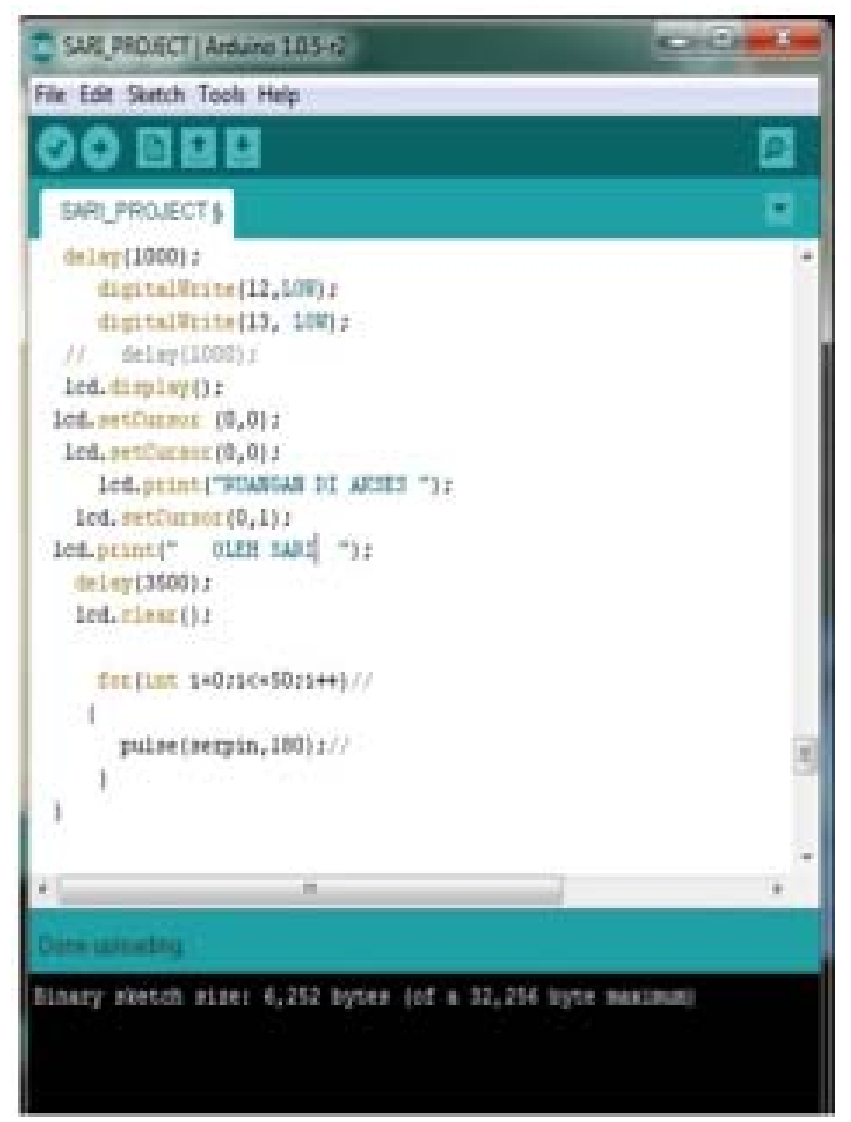

Gambar 14. Uploading Compile Sukses

\section{UJI COBA SMARTCARD RFID} digunakan.

Berikut ini merupakan gambaran tampilan alat yang sedang menyala dan siap untuk

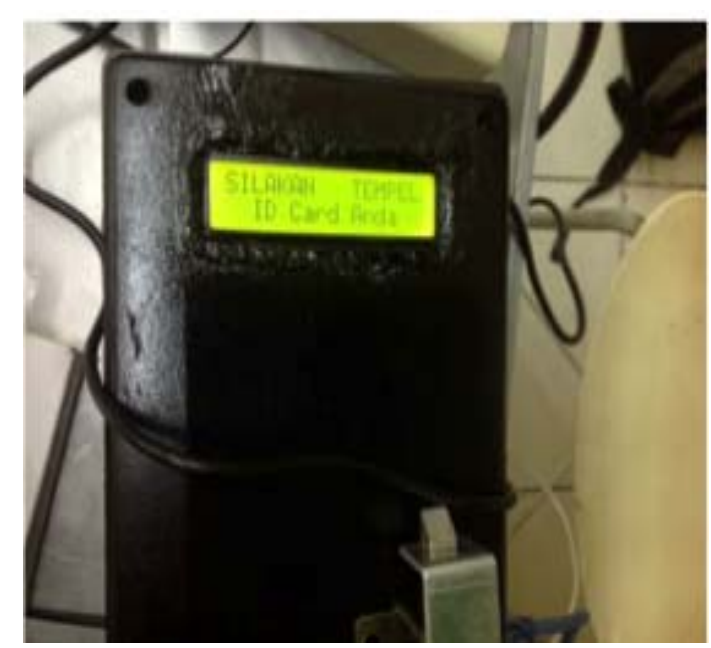

Gambar 15. Tampilan RFID Reader

Dari gambar 15 diatas merupakan tampilan rfid reader, dimana system kerja rfid reader ini adalah dengan mendekatkan smartcard rfid pada rfid reader, dan akan menampilkan displayer text " RUANGAN DI AKSES OLEH CUSTOMER”. Seperti gambar 16 dibawah : 


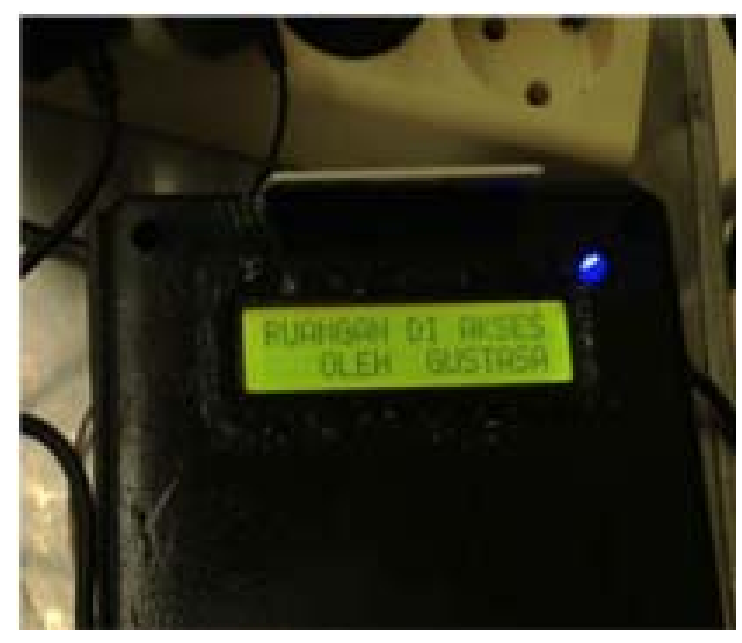

Gambar 16. Tampilan Displayer Text yang telah diakses

Setelah Smartcard Rfid terbaca, maka solenoid akan bergerak dan membuka pintu secara otomatis, seperti gambar 17 dibawah ini:

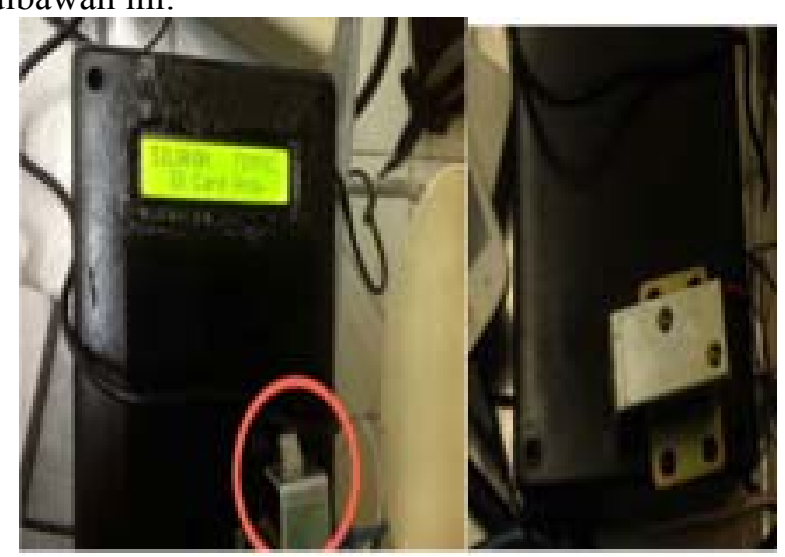

Gambar 17. Tampilan Solenoid Terbuka

Tahapan selanjutnya adalah data akan tersimpan dalam database system, seperti gambar 18 dibawah ini :

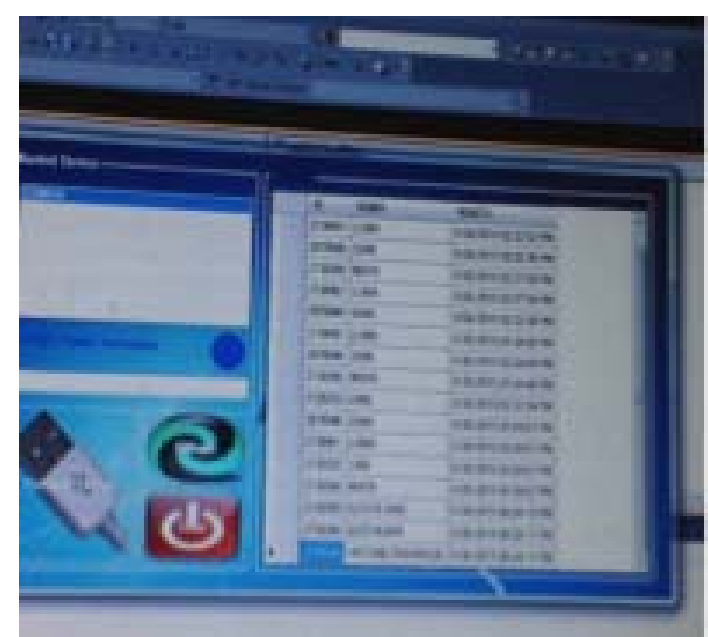

Gambar 18. Tampilan Database 


\section{KESIMPULAN}

Berdasarkan analisa yang telah diuraikan sebelumnya, maka dapat diambil kesimpulan perihal Analisa Sistem Lock Unlock Pintu Menggunakan Rfid Pada Perguruan Tinggi Raharja sebagai berikut

1. Sistem lock unlock pintu pada Perguruan Tinggi Raharja masih menggunakan kunci manual.

2. Untuk mengkoneksikan arduino dengan rfid dibutuhkan sebuah software yaitu software arduino Arduino 1.0, dan terbukti jika tidak terjadi kesalahan pada saat program di compile itu menandakan bahwa arduino telah terkoneksi ke rfid.

Manfaat yang didapat dari penelitian ini adalah penulis dapat menambah pengetahuan dan wawasan dalam penerapan teknologi yang sudah ada.Selain itu juga manfaat yang didapat yaitu dengan adanya sistem Lock Unlock Pintu dengan menggunakan RFID dapat membantu dan mempermudahkan petugas membuka dan menutup pintu tanpa harus kesulitan mencari kunci yang sesuai terlebih dahulu.Serta tidak membuat pribadi Raharja menunggu lama untuk masuk ke dalam ruangan kelas pada Perguruan Tinggi Raharja.Selain dari pada itu Dengan hadirnya sistem ini diharapkan dapat menjadi sebuah inovasi baru yang berguna pada Perguruan Tinggi Raharja dan dapat memperbaiki kekurangan sistem yang sudah ada serta dapat memberikan pelayanan yang maksimal kepada seluruh pribadi raharja.

\section{DAFTAR PUSTAKA}

1. Abri, Putra, Sipahutar . Johannes, Setiawardhana, dan B. Dwi. Kurnia. "Sistem Identifikasi Smartcard-Rfid Dan Pengenalan Tanda Tangan Menggunakan Metode Backpropagation Dengan Kohonen Sebagai Pembanding ". Politeknik Elektronika Negeri Surabaya - Institut Teknologi Sepuluh Nopember (ITS) Surabaya. 2011. (Tanggal akses 5 Maret 2015).

2. D. Darmawan, Denny. Ramdhani. M, dan M. Ary. M. "Perancangan Sistem Pengaman Pintu Menggunakan Rfid Tag Card Dan Pin Berbasis Mikrokontroler Avr Atmega 8535". Fakultas Elektro danKomunikasi-Institut Teknologi Telkom. 2010. (Tanggal akses 5 Maret 2015).

3. K. Johan. Wijaya dan S.Nugoho. "Pengaman Rumah Menggunakan Kunci Elektronik Berbasis Rfid". AMIKk GI Mdp, Indonesia. 2012. (Tanggal akses 5 Maret 2015).

4. Komaeni, Nurul. "Analisa Perpustakaan Menggunakan Acr 122u Berbasis Rfid Pada Perguruan Raharja”. Perguruan Tinggi Raharja. 2015. (Tanggal akses 5 Maret 2015).

5. Nasution, Claudia, D.T. Puji Rahayu,dan S.J. Friscilia. "Perancangan Dan Pembuatan Simulasi Sistem Keamanan Pintu Dengan Sistem Calling Seluler Menggunakan Rfid (Radio Frequency Identification) Dan Password Berbasis Mikrokontroler ATMEGA16". Politeknik Negeri Medan .2014. (Tanggal akses 5 Maret 2015).

6. P. Rahmadani Anggun, dan Napitupulu, Rafika. "Rancang Bangun Sistem Keamanan Pintu Dengan Menggunakan Rfid Berbasis Mikrokontroler AT89S52". Politeknik Negeri Medan. 2013. (Tanggal akses 5 Maret 2015).

7. Riza, Muharris. "Perancangan Keamanan Pintu Otomatis Berbasis Rfid (Radio Frekuensi Identifica Tion)".Universita s Ubudiyah, Indonesia. 2014. (Tanggal akses 5 Maret 2015).

8. R. S. OmriI Tua. "Perancangan Sistem Keamanan Pintu Menggunakan Rfid Berbasis Mikrokontroler ATMEGA 8235. Universitas Sumatera Utara. 2011. (Tanggal akses 5 Maret 2015).

9. S. Damas. Cahyo, Yuniarto,ST. MT. "Aplikasi Radio Frequency Identification Dan Infrared Sebagai Pengaman Pintu Keluar Masuk Berbasis Mikrokontroler AVR ATMEGA 16 Pada Miniatur Kompleks Perumahan Modern". Universitas Diponegoro Semarang, Indonesia. 2012. (Tanggal akses 5 Maret 2015).

10. Suyoko, Didik . "Alat Pengaman Pintu Rumah Menggunakan Rfid(Radio Frequency Identifica Tion) $125 \mathrm{Khz}$ Berbasis Mikrokontroler A TMEGA328". Universitas Negeri Yogyakarta. 2012. (Tanggal akses 5 Maret 2015). 